\title{
MACHINE LEARNING MODEL TO PREDICT THE DIVORCE OF A MARRIED COUPLE
}

Nahum Flores

Student, Artificial Intelligence Group, Faculty in Systems Engineering and Computer Science,

National University of San Marcos. Lima, (Peru).

E-mail:nahum.flores@unmsm.edu.pe

ORCID: https://orcid.org/0000-0002-5807-4323

Sandra Silva

Student, Artificial Intelligence Group, Faculty in Systems Engineering and Computer Science,

National University of San Marcos. Lima, (Peru).

E-mail: sandra.silva3@unmsm.edu.pe

ORCID: https://orcid.org/0000-0003-0253-7883

Recepción: 09/12/2020 Aceptación: 10/03/2021 Publicación: 07/05/2021

\section{Citación sugerida:}

Flores, N., y Silva, S. (2021). Machine learning model to predict the divorce of a married couple. 3C Tecnología. Glosas de innovación aplicadas a la pyme, Edición Especial, (mayo 2021), 83-95. https://doi. $\mathrm{org} / 10.17993 / 3$ ctecno.2021.specialissue7.83-95 


\section{ABSTRACT}

Divorce usually impacts the closest family members, over the years the divorce rate has increased dramatically, especially in the last two decades and worsening with the pandemic, where there has been a significant increase in the divorce rate in many countries of the world. We draw on Yöntem's work where he poses 56 questions as predictors of divorce. In addition, we make use of 4 automatic learning models (perceptron, logistic regression, neural networks and randomized forest) and 3 hybrid models based on voting criteria. Each of these models was trained in 5 different scenarios, making a total of 35 experiments, the best performance obtained in terms of precision, sensitivity and specificity is 0.9853 , 1.0 and 0.9667 respectively, corresponding to the perceptron model and a hybrid model; however, although the results show a high performance, the context, the amount of data and the country in which the data were collected must be considered.

\section{KEYWORDS}

Machine learning, Neural networks, Divorce predict, Voting. 


\section{INTRODUCTION}

The divorce rate worldwide has increased dramatically in recent years. This assertion is based in figures. First, is the American divorce rate. If we compare the figures for 2018 with those of 1900, it shows that there are four times more divorced women (Schweizer, 2020). In Spain, this rate doubled (2018) compared to 2000 (INE, 2018). In Mexico, such rate tripled from 2000 to 2019 (INEGI, 2019) and in Peru the number of divorces registered in 2018 (INEI, 2018) is eight times higher than those registered in 2000 (INEI, 2010).

The current pandemic context has only exacerbated this phenomenon, as the confinement has brought with its greater increase. This applies for the United States, which, in couples with at least 5 years of marriage, registered $16 \%$ more divorces in the third quarter of 2020 than in the same period of 2019 and an increase of $5 \%$ in couples with children that have less than 18 years (Legal Templates, 2020). An even more noticeable case occurs in Xi'an (China) where divorce requests have increased to such an extent that they have reached their daily limit (Díez, 2020). Naturally, this situation has consequences that can affect close members of the families involved (Sánchez, 2019).

In this regard, different studies have identified multiple factors to predict divorce. One of the most significant works was that of Gottman. He identified "The Four Horsemen of the Apocalypse" that can end a marriage: criticism, contempt, stonewalling and defensiveness (Gottman \& Silver, 2014). Using just these four variables in a longitudinal study conducted with newlywed couples, Gottman estimated which couples would have an early divorce with $85 \%$ accuracy. Gottman also identified that quality sexual satisfaction, love, and passion in marriages depend directly (by 70\%) on the quality of friendship they have (Gottman \& Silver, 2015). On the other hand, there are studies that show infidelity as the main ground for divorce. This is not surprising: infidelity is the leading cause of divorce in the United States (Mark, Janssen, \& Milhausen, 2011) as well as in more than 160 cultures (Betzig, 1989), because it has negative effects on the relationship, and can be the most feared and devastating experience in a matrimony (Pittman, 1994), thus leading it to an end (Zordan \& Strey, 2011).

In the last decade, the use of Machine Learning models in psychology has become popular, leaving behind numerous methods of estimation, statistical analysis and data mining for 
predictions. In the first place is Amiriparian, who used audio spectrograms to diagnose bipolar disorder (Amiriparian et al., 2019), obtaining an Unweighted Average Recall (UAR) of $46.2 \%$. Second are Eastwick and Joel, who used a random forest method to predict the appereance of a relationship based on traits and preferences; out of 192 couples, it was able to predict $4 \%$ to $18 \%$ of actor variance (average tendency to romantically desire other people) and $7 \%$ to $27 \%$ of the partner variance (to be desired by other people) (Joel, Eastwick, \& Finkel, 2017). Finally, Flesia's work predicted the stress levels that are caused by COVID-19 from 18 psychosocial variables, achieving a sensitivity of $76 \%$.

For the particular case of the prediction of divorce, we checked the following background: the work of Großmann et al. (2019), which used a linear regression model to predict the future of a relationship based on the analysis of personality traits, the work of Yöntem et al. (2019) with ANN models that achieved a precision of $98.85 \%$ and the work of Narendran, Abilash \& Charulatha (2020) that made use of a voting classifier with decision trees, bagging classifier and XGBoost prediction models, achieving a performance of $94.14 \%$.

Using fresher classification methods, the present work aims to compare the high performance obtained with an analysis based on the correlation of variables, making available the proposed models and their respective trained results.

\section{MATERIALS AND METHODS}

\subsection{DATASET}

In this research we will use the same dataset as the one in Yöntem's et al. work (2019) which is composed of 54 questions. 6 of them can be seen in Table 1: they were answered by 170 people -84 divorced and 86 married--. As divorce predictor, each question had different probabilities of impact. Answers are on a 5 -point scale $(0=$ Never, $1=$ Rarely, $2=$ Average, $3=$ Often, $4=$ Always).

Table 1. Questions formulated in Yöntem's work.

\begin{tabular}{|c|c|}
\hline ID & Questions \\
\hline Atr1 & If one of us apologizes when our discussion deteriorates, \\
the discussion ends.
\end{tabular}




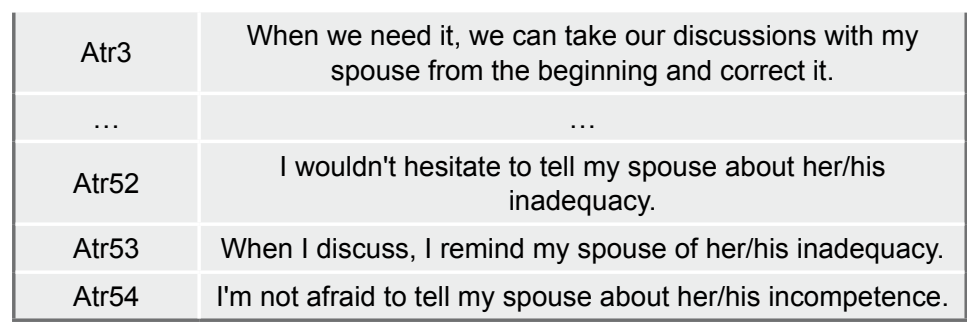

Source: adapted from (Yöntem et al., 2019).

\subsection{PREPROCESSING}

Data normalization is one of the preprocessing approaches where the data is scaled or transformed to obtain an equal contribution from each characteristic, thus translating into a significant improvement in the performance of Machine Learning algorithms (Singh \& Singh, 2019). In this work, the 54 questions contain numerical data between 0 to 4 , values that were re-scaled between -1 and 1, as shown in Figure 1.

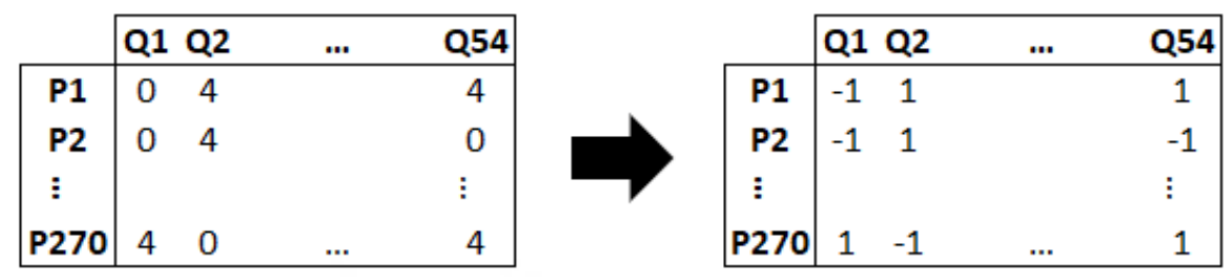

Figure 1. Normalization of the answers.

Source: own elaboration.

\subsection{FEATURE SELECTION}

Considering each question as a characteristic, we use Pearson's correlations for the selection. Thus, we measure the degree of relationship between the variables (Liu et al., 2020). Table 2 shows the 20 variables with the highest correlation.

Table 2. Question with the highest correlation.

\begin{tabular}{|c|l|l|l|}
\hline Id & Score & Id & Score \\
\hline Atr22 & 0.7853 & Atr42 & 0.6423 \\
\hline Atr54 & 0.7685 & Atr48 & 0.6336 \\
\hline Atr28 & 0.7621 & Atr53 & 0.6114 \\
\hline Atr44 & 0.7530 & Atr47 & 0.5827 \\
\hline Atr34 & 0.7498 & Atr52 & 0.5755 \\
\hline Atr32 & 0.7397 & Atr45 & 0.5102 \\
\hline Atr50 & 0.7254 & Atr43 & 0.4822 \\
\hline Atr31 & 0.6992 & Atr7 & 0.4280 \\
\hline
\end{tabular}




\begin{tabular}{|c|c|c|c|}
\hline Atr51 & 0.6841 & Atr46 & 0.4003 \\
\hline Atr49 & 0.6748 & Atr6 & 0.2871 \\
\hline
\end{tabular}

Source: own elaboration.

\subsection{CLASSIFICATION}

For the classification, this work uses four models of Machine Learning. The first is the Perceptron model, with a stop criterion of $1 \mathrm{e}-4$. The second model is a logistic regression with lbfgs as the optimization parameter. The third model are neural networks, composed of 7 layers, as seen in Figure 2, all with a sigmoidal activation function and 30 epochs for their training. The fourth is a Random Forest model with 100 estimators and a depth of 2 . Generally, hybrid models based on voting criteria have superior performance (Kuncheva \& Rodríguez, 2012; Liu, Reviriego, Lombardi, \& Hernandez, 2020), for which 3 hybrid models were created from the 4 models mentioned. The classification models can be seen in Table 4.

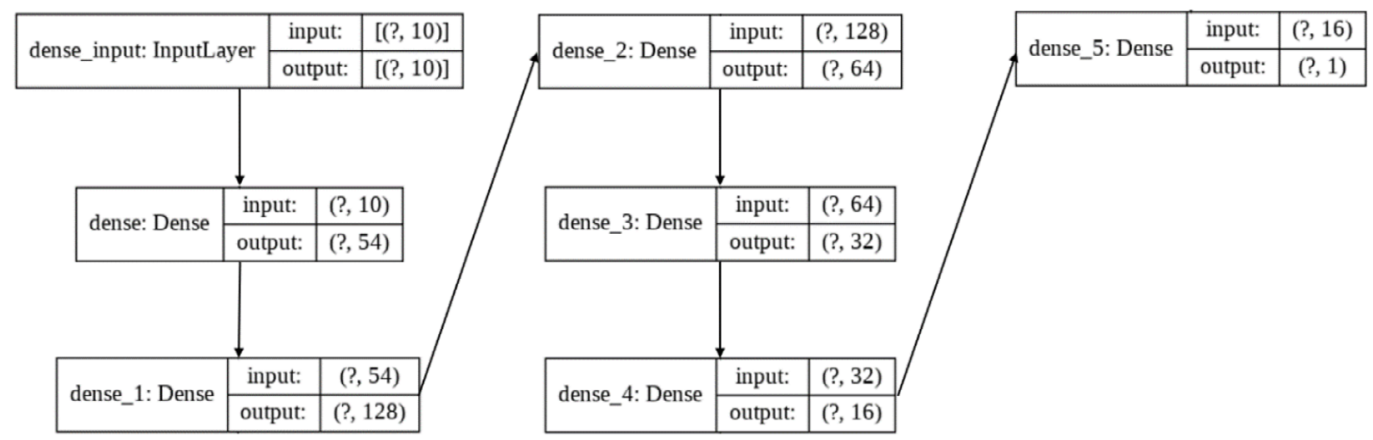

Figure 2. Architecture of a neural network model.

Source: own elaboration.

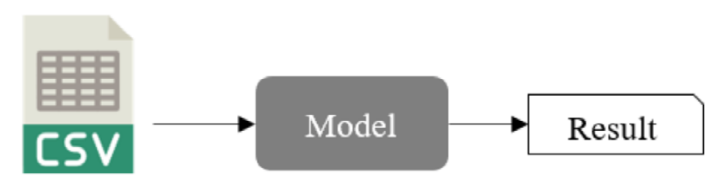

Preprocessed

dataset

Figure 3. Training scheme for each model.

Source: own elaboration.

For the training, test and training data was randomly divided, in the proportions shown in Table 3. Each model was trained with the scheme in Figure 3.

Table 3. Proportion of training and test data. 


\begin{tabular}{|c|c|c|c|c|c|c|}
\hline Label & & \multicolumn{5}{|c|}{ Proportion (\%) } \\
\hline \multirow{2}{*}{ Divorced } & Training & 42 & 50 & 59 & 67 & 76 \\
\hline & Test & 42 & 34 & 25 & 17 & 8 \\
\hline \multirow{2}{*}{ Married } & Training & 43 & 52 & 60 & 69 & 77 \\
\hline & Test & 43 & 34 & 26 & 17 & 9 \\
\hline
\end{tabular}

Source: own elaboration.

Table 4. Models used for prediction.

\begin{tabular}{|c|c|}
\hline ID & Models \\
\hline M1 & Logistic Regression \\
\hline M2 & Neural Networks \\
\hline M3 & Random Forest \\
\hline M4 & Perceptron, Logistic Regression and Neural Networks \\
\hline H1 & Perceptron, Neural Networks and Random Forest \\
\hline H2 & Perceptron, Logistic Regression and Random Forest \\
\hline H3 & Perceptron \\
\hline
\end{tabular}

Source: own elaboration.

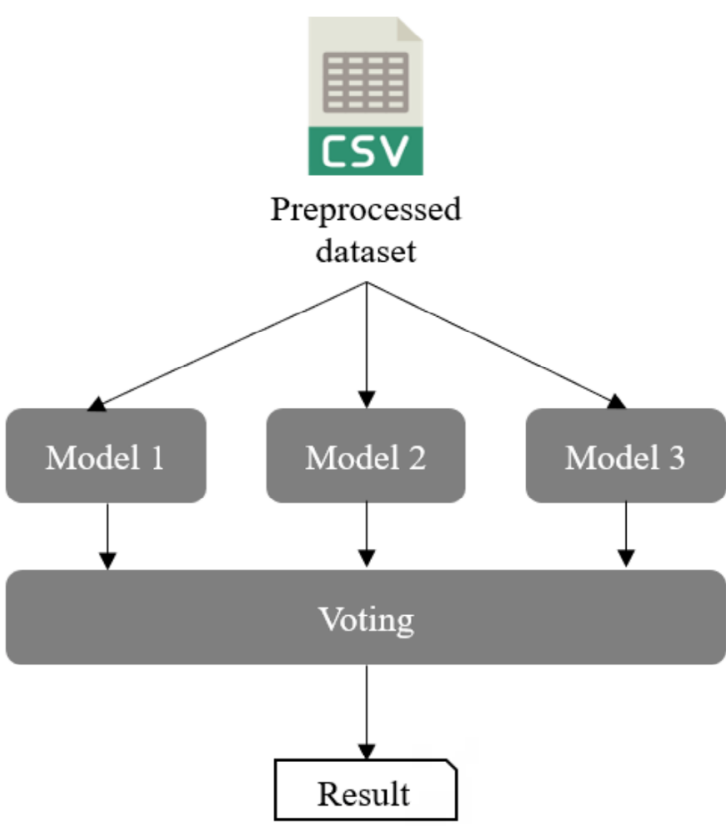

Figure 4. Voting criteria for hybrid models.

Source: own elaboration.

The proposed model was implemented using Python 3 in Google Colab (Carneiro, Medeiros, \& Nepomuceno, 2018) using a 2.3 GHz Xeon CPU with 13gb RAM and a 16gb RAM Nvidia Tesla V100 graphics card. 


\subsection{EVALUATION}

To measure the performance of the classification, the proposed model used performance metrics in terms of sensitivity (Sen), specificity (Spe) and Accuracy (Acc).

A divorced person properly classified is called "true positive" (TP). A divorced person that is not properly classified is called "true negative" (TN). When a divorced person is classified as married, it is called a "false negative" (FN), and when a married person is classified as divorced, it is called a "false positive" (FP).

Sensitivity shows divorced people correctly classified, defined as (Lyusin \& Ovsyannikova, 2016):

$$
\text { Sensitivity }=\frac{\mathrm{TP}}{\mathrm{TP}+\mathrm{FN}}
$$

Specificity shows divorced and married people properly classified. It is calculated as follows (Glaros \& Kline, 1988):

$$
\text { Specificity }=\frac{\mathrm{TN}}{\mathrm{TN}+\mathrm{FP}}
$$

Accuracy indicates the ratio of correctly classified people, obtained with the formula (Pedersen, Cheng, \& Rasmussen, 1989):

$$
\text { Accuracy }=\frac{\mathrm{TP}+\mathrm{TN}}{\mathrm{TP}+\mathrm{FP}+\mathrm{TN}+\mathrm{FN}}
$$

On the other hand, hybrid models are evaluated by the voting criterion (see Figure 4), where the label that was repeated the most is selected.

\section{RESULTS}

In this work, multiple experiments were generated with the four models defined in the "classification" section. These were trained with the proportions defined in Table 3. When training the model with the Yöntem work dataset, the results of Table 5 are obtained.

Table 5. Accuracy results of the training.

\begin{tabular}{|c|c|c|c|c|c|}
\cline { 2 - 7 } \multicolumn{1}{c|}{} & \multicolumn{5}{c|}{ Training/Test (\%) } \\
\hline Model & $\mathbf{5 0 / 5 0}$ & $\mathbf{6 0 / 4 0}$ & $\mathbf{7 0 / 3 0}$ & $\mathbf{8 0 / 2 0}$ & $\mathbf{9 0 / 1 0}$ \\
\hline Perceptron & 0.9529 & 0.9853 & 0.9608 & 0.9412 & 0.9412 \\
\hline Logistic Regression & 0.9412 & 0.9559 & 0.9804 & 0.9706 & 0.9412 \\
\hline
\end{tabular}




\begin{tabular}{|c|c|c|c|c|c|}
\hline Neural Networks & 0.9647 & 0.9559 & 0.9804 & 0.9706 & 0.9412 \\
\hline Random Forest & 0.9294 & 0.9412 & 0.9804 & 0.9706 & 0.9412 \\
\hline $\mathrm{H} 1^{*}$ & 0.9647 & 0.9853 & 0.9804 & 0.9706 & 0.9412 \\
\hline $\mathrm{H} 2^{*}$ & 0.9412 & 0.9706 & 0.9804 & 0.9706 & 0.9412 \\
\hline $\mathrm{H} 3^{*}$ & 0.9412 & 0.9706 & 0.9804 & 0.9706 & 0.9412 \\
\hline
\end{tabular}

Source: own elaboration.

Table 6. Sensitivity results of the training.

\begin{tabular}{|c|c|c|c|c|c|}
\cline { 2 - 7 } \multicolumn{1}{c|}{} & \multicolumn{5}{c|}{ Training/Test (\%) } \\
\hline Model & $\mathbf{5 0 / 5 0}$ & $\mathbf{6 0 / 4 0}$ & $\mathbf{7 0 / 3 0}$ & $\mathbf{8 0 / 2 0}$ & $\mathbf{9 0 / 1 0}$ \\
\hline Perceptron & 0.9783 & 1.0000 & 0.9630 & 0.9444 & 1.0000 \\
\hline Logistic Regression & 1.0000 & 1.0000 & 1.0000 & 1.0000 & 1.0000 \\
\hline Neural Networks & 1.0000 & 1.0000 & 1.0000 & 1.0000 & 1.0000 \\
\hline Random Forest & 1.0000 & 1.0000 & 1.0000 & 1.0000 & 1.0000 \\
\hline H1 & 1.0000 & 1.0000 & 1.0000 & 1.0000 & 1.0000 \\
\hline H2 $^{*}$ & 1.0000 & 1.0000 & 1.0000 & 1.0000 & 1.0000 \\
\hline H3 $^{*}$ & 1.0000 & 1.0000 & 1.0000 & 1.0000 & 1.0000 \\
\hline
\end{tabular}

Source: own elaboration.

Table 7. Sensitivity results of the training.

\begin{tabular}{|c|c|c|c|c|c|}
\cline { 2 - 6 } \multicolumn{1}{c|}{} & \multicolumn{5}{c|}{ Training/Test (\%) } \\
\hline Model & $\mathbf{5 0 / 5 0}$ & $\mathbf{6 0 / 4 0}$ & $\mathbf{7 0 / 3 0}$ & $\mathbf{8 0 / 2 0}$ & $\mathbf{9 0 / 1 0}$ \\
\hline Perceptron & 0.9231 & 0.9667 & 0.9583 & 0.9375 & 0.9000 \\
\hline Logistic Regression & 0.8718 & 0.9000 & 0.9583 & 0.9375 & 0.9000 \\
\hline Neural Networks & 0.9231 & 0.9667 & 0.9583 & 0.9375 & 0.9000 \\
\hline Random Forest & 0.8462 & 0.8667 & 0.9583 & 0.9375 & 0.9000 \\
\hline $\mathrm{H}^{*}$ & 0.9231 & 0.9667 & 0.9583 & 0.9375 & 0.9000 \\
\hline $\mathrm{H} 2^{*}$ & 0.8718 & 0.9333 & 0.9583 & 0.9375 & 0.9000 \\
\hline $\mathrm{H}^{*}$ & 0.8718 & 0.9333 & 0.9583 & 0.9375 & 0.9000 \\
\hline
\end{tabular}

Source: own elaboration.

\section{CONCLUSIONS}

In this work, 7 models were used for the prediction of divorce, trained with the dataset from Yöntem's et al. (2019) work and the dataset collected in this research. Each of these models was trained in 5 different scenarios, making a total of 35 experiments. Among these, the best results were obtained with the perceptron model and the first hybrid model; however, due to the amount of data, the hybrid models did not perform better. 
Although the results show high performance, the context, the amount of data and the country in which the data was collected must be considered. In order to feed the dataset to retrain the models, in the future we plan to collect couple's data from different countries, evaluating their performance.

Divorce is a major problem, especially in a context of confinement, where the rates of divorced couples have increased considerably, indirectly affecting the closest members of the family (such as children). Also, couples can lose a lot by going through a divorce process. This study can help them prevent these consequences. The prediction models in this study would help people decide whether to make the decision to marry or not, give them the opportunity based on compatibility to have a successful marriage.

The best performance of a model was obtained by using the 60/40 ratio of the training and test data. The results were 0.9853 precision, 1.0 sensitivity and 0.9667 specificity. We make the models and training results available in our GitHub repository (https://github. com/NahumFGz/DivorcePredict).

\section{REFERENCES}

Amiriparian, S., Awad, A., Gerczuk, M., Stappen, L., Baird, A., Ottl, S., \& Schuller, B. (2019). Audio-based Recognition of Bipolar Disorder Utilising Capsule Networks. IEEE Xplore. https://doi.org/10.1109/ijcnn.2019.8852330

Betzig, L. (1989). Causes of Conjugal Dissolution: A Cross-cultural Study. Current Anthropology, 654-676.

Carneiro, T., Medeiros, R., \& Nepomuceno, T. (2018). Performance Analysis of Google Colaboratory as a Tool for Accelerating Deep Learning Applications. IEEE, 9. https://doi.org/10.1109/ACGESS.2018.2874767

Díez, P. M. (2020, March 21). Divorce epidemic in China due to coronavirus quarantines. ABC. https://www.abc.es/sociedad/abci-epidemia-divorcios-china-cuarentenascoronavirus-202003200152_noticia.html 
Glaros, A., \& Kline, R. (1988). Understanding the accuracy of tests with cutting scores: The sensitivity, specificity, and predictive value model. Fournal of Clinical Psychology, 44(6), 1013-1023. https://doi.org/10.1002/1097-4679(198811)44:6<1013::aidjclp2270440627>3.0.co;2-z

Gottman, J., \& Silver, N. (2014). How to Maintain Love. Secrets from the Love Lab. Varlik Publications.

Gottman, J., \& Silver, N. (2015). Seven Principles of Keeping Married. Varlık Publications.

Großmann, I., Hottung, A., \& Krohn-Grimberghe, A. (2019). Machine learning meets partner matching: Predicting the future relationship quality based on personality traits. PLOS ONE, 14(3).

INE. (2018, September 30). Eurostat Statistics Eplained. https://www.ine.es/prodyser/espa_ cifras/2018/14/

INEGI. (2019). INEGI. Instituto Nacional de Estadística y Geografia. https:/ / www.inegi.org.mx/ temas/nupcialidad/

INEI. (2010). National Institute of Statistics and Informatics. https://www.inei.gob.pe/media/ MenuRecursivo/publicaciones_digitales/Est/Lib 1045/cap04.pdf

INEI. (2018). National Institute of Statistics and Informatics. https://www.inei.gob.pe/media/ MenuRecursivo/publicaciones_digitales/Est/Lib1698/libro.pdf

Joel, S., Eastwick, P., \& Finkel, E. (2017). Is Romantic Desire Predictable? Machine Learning Applied to Initial Romantic Attraction. Psychological Science, 28(10), 14781489 .

Kuncheva, L., \& Rodríguez, J. (2012). A weighted voting framework for classifiers ensembles. Knowledge and Information Systems, 38(2), 259-275. https:// doi.org/10.1007/ s10115-012-0586-6

Legal Templates. (2020, July 29). US Divorce Rates Soar During COVID-19 Crisis. https:// legaltemplates.net/resources/personal-family/divorce-rates-covid-19/\#divorcesincrease-in-couples-with-children 
Liu, S., Reviriego, P., Lombardi, F., \& Hernandez, J. A. (2020). Voting Margin: A Scheme for Error-Tolerant k Nearest Neighbors Classifiers for Machine Learning. IEEE Transactions on Emerging Topics in Computing https://doi.org/10.1109/ tetc. 2019.2963268

Liu, Y., Mu, Y., Ghen, K., Li, Y., \& Guo, J. (2020). Daily Activity Feature Selection in Smart Homes Based on Pearson Correlation Coefficient. Neural Processing Letters, 2(1771-1787), 51. https://doi.org/10.1007/s11063-019-10185-8

Lyusin, D., \& Ovsyannikova, V. (2016). Measuring two aspects of emotion recognition ability: Accuracy vs. sensitivity. Learning and Individual Differences, 52, 129-136. https:// doi.org/10.1016/j.lindif.2015.04.010

Mark, K. P., Janssen, E., \& Milhausen, R. R. (2011). Infidelity in Heterosexual Couples: Demographic, Interpersonal, and Personality-Related Predictors of Extradyadic Sex. Archives of Sexual Behavior, 40(5), 971-982. https://doi.org/10.1007/s10508-0119771-z

Narendran, D. J., Abilash, R., \& Gharulatha, B. S. (2020). Exploration of Classification Algorithms for Divorce Prediction. Proceedings of International Conference on Recent Trends in Machine Learning, IoT, Smart Cities and Applications, 291-303. https://doi. org/10.1007/978-981-15-7234-0_25

Pedersen, P., Gheng, G., \& Rasmussen, J. (1989). On Accuracy Problems for SemiAnalytical Sensitivity Analyses. Mechanics of Structures and Machines, 17(3), 373-384. https://doi.org/10.1080/089054508915647

Pittman, F. (1994). Private Lies: Infidelity and the Betrayal of Intimacy. Artes Médicas.

Sánchez, T. (2019). Consequences of divorce on children. The need for a new way of intervening: The joint work of a lareyer and a psychologist. https://eprints.ucm.es/54965/

Schweizer, V. (2020). Divorce: More than a Century of Change, 1900-2018. Family Profil, 1-2. https://www.bgsu.edu/content/dam/BGSU/college-of-arts-and-sciences/ NCFMR/documents/FP/schweizer-divorce-century-change-1900-2018-fp-20-22. pdf 
Singh, D., \& Singh, B. (2019). Investigating the impact of data normalization on classification performance. Applied Soft Computing, 105524. https://doi.org/10.1016/j. asoc.2019.105524

Yöntem, M., Adem, K., İlhan, T., \& Kılıçarslan, S. (2019). Divorce Prediction Using Correlation Based Feature Selection And Artificial Neural Networks. Nevşehir Hacı Bektaş Veli University SBE Dergisi, 9(1), 259-273. https://dergipark.org.tr/tr/pub/ nevsosbilen/issue/46568/549416

Zordan, E.P., \& Strey, M.N.(201 1).Maritalseparation:Aspectsinvolved in thisdecision, reversion and future projects. https://www.semanticscholar.org/paper/Separa\%C3\%A7\%C3\%A3oconjugal\%3A-aspectos-implicados-nessa-e-Zordan-Strey/6e25b5932d14c86e3aa3f $191 \mathrm{bb} 9761876 \mathrm{e} 76 \mathrm{eb9c}$ 